\title{
EL REUSO DE MATERIALES Y ESTRUCTURAS ANTIGUAS EN LAS IGLESIAS ALTOMEDIEVALES DE GALICIA. CASOS, PROBLEMAS Y MOTIVACIONES
}

\author{
JOSÉ CARLOS SÁNCHEZ PARDO ${ }^{(1)}$
}

Resumen:

En este trabajo se realiza una revisión global y conjunta del habitual fenómeno del reuso de piezas y estructuras de época antigua en iglesias altomedievales de Galicia desde una perspectiva arqueológica. Se trata de dos ámbitos muy ligados entre sí y que sin embargo suelen estudiarse de manera independiente. Para ello exponemos en una primera parte la problemática arqueológica que nos encontramos a la hora de analizar este tipo de reutilizaciones, especialmente la falta de cronologías y contextos estratigráficos. A continuación se presentan los casos en los que existen evidencias más sólidas para hablar de una reutilización en una iglesia de época altomedieval en Galicia. Finalmente, se explora el amplio debate sobre las razones y significados de este tipo de práctica y se presentan los distintos niveles de interpretación de este fenómeno (funcional, estéticosuntuario e ideológico) en relación con el contexto social del período altomedieval en el Noroeste de la Península Ibérica.

Palabras clave: spolia, reutilización, iglesias altomedievales, técnicas constructivas, aras romanas, élites sociales

Abstract:

\begin{abstract}
The reuse of ancient materials and structures in the early medieval churches of Galicia. Cases, problems and explainations

This paper intends to carry out a global review, from an archaeological perspective, of the common issue of the reuse of ancient materials and structures in the early medieval churches of Galicia (Spain). Both kind of reuse (pieces and structures/buildings) are deeply related between them, but, surprisingly, they are usually studied by separate. In the first part of this paper, the archaeological problems when analyzing these kind of reuses are discussed, specially those regarding the lack of chronological accuracy as well as the scarcity of clear stratigraphical sequences. Then, the most reliable cases of early medieval reuse of ancient materials and structures in galician churches are explored. Finally, the debate on the reasons and meanings of the reuse is presented, discussing the different interpretative levels (functional, aesthetic-sumptuary and ideological) in relation to the social context of early medieval Northwest Iberia.
\end{abstract}

Keywords: spolia, reuse, early medieval churches, constructive techniques, roman altar, social elites

\section{INTRODUCCIÓN}

Existe una amplia bibliografía sobre el habitual fenómeno de la reutilización de materiales antiguos (spolia) en las construcciones de la Europa tardoantigua y altomedieval (BRENK 1987; GREENHALGH 1989; CABALlERO \& SÁNCHEZ 1990; WARD-PERKINS 1999; CUTLER 1999; EATON 2000; ARAGUAS 2007; DOMINGO MAGAÑA 2009; ChaVARría 2009: 108-109; SASTRE 2011; Utrero \& SASTRE 2012). Concretamente, los edificios que más concentran este tipo de prácticas en este período son las iglesias, ya que constituyen una de las principales y más extendidas expresiones arquitectónicas de la sociedad y del poder de estos siglos. A su vez, los materiales más frecuentemente reutilizados son aquellos del período romano, dada la amplia extensión de las construcciones de esa etapa y la disponibilidad de material que ofrecían a los constructores de los siglos posteriores.

Un tema paralelo, y muy relacionado con el de los spolia es el de la reutilización de estructuras y lugares antiguos en el período tardoantiguo y altomedieval (BRADLEY 1987, 1993: 114-129; WILLIAMS 1998; FUENTES DOMÍNGUEZ 2000; EFFros 2001; JiMENEZ, SALES 2004; Bell 2005; ChAVARría 2007). De nuevo, las iglesias se muestran como el principal tipo de edificación que reutiliza estructuras y yacimientos antiguos.

En términos generales, la posición de los distintos autores que estudian ambos temas varía según el peso que otorgan a explicaciones más o menos pragmáticas (o por el contrario, más o menos ideológicas) a estas reutilizaciones de materiales y estructuras antiguas durante los siglos V y X. Sin

\footnotetext{
(1) Investigador postdoctoral Marie Curie CIG / Ramón y Cajal, Departamento de Historia I, Universidad de Santiago de Compostela, email: josecarlos.sanchez@usc.es ${ }^{1}$ Este artículo há sido elaborado en el marco del proyecto: "Early Medieval Achurches: History, Archaeology and Heritage" (EMCHAHE) financiado por una ayuda europea Marie Curie Career Integration Grant (Grant agreement - PCIG12 - GA - 2012 - 334068) de la Agencia Europea de Investigación (Frame Program 7), con una duración de 4 años $(2013$ - 2017) y desarrollado en la Universidad de Santiago de Compostela. El autor desea expresar su agradecimiento a los revisores anónimos por los valiosos comenarios que han ayudado a mejorar este artículo.)
} 
embargo, resulta llamativo que no existan trabajos que consideren ambas prácticas en conjunto.

En este artículo pretendemos explorar desde un punto de vista arqueológico y global el fenómeno de la reutilización de elementos y estructuras antiguas en las iglesias altomedievales de Galicia. Se trata de un tema poco estudiado en esta zona, con excepción del ya antiguo trabajo de Manuel Castiñeiras (CASTIÑEIRAS 1990) y la inclusión de diversos ejemplos gallegos en algunas síntesis de la Península Ibérica (CABALLERO \& SÁNCHEZ 1990; SASTRE 2011; Utrero \& SASTRE 2012). Igualmente, como trataremos de mostrar, se trata de un tema a menudo muy problemático y complicado de analizar, debido especialmente a la falta de contextos arqueológicos claros. Pese a todo ello, consideramos que esta cuestión posee un gran interés para comprender muchos aspectos de la sociedad de este período, tales como la economía, tecnologías, cultura, mentalidades...

En ese sentido, este artículo constituye una simple pero necesaria primera aproximación general a este tema en esta región. En la primera parte del mismo realizaremos una revisión crítica de las evidencias disponibles, así como de sus diferentes problemáticas arqueológicas. Para mayor claridad en la exposición, estableceremos una diferenciación dentro de esta primera parte entre el reuso de materiales y el de estructuras por parte de la iglesia altomedieval. Sin embargo volvemos a recordar que se trata de una distinción artificial y en parte falaz ya que muchas de las iglesias que reutilizan materiales están situadas precisamente encima o en las inmediaciones de un yacimiento arqueológico. En ese sentido, el problema del reuso de materiales está muy ligado al propio conocimiento del sustrato arqueológico de construcción de la iglesia, como veremos a continuación.

En una segunda parte abordaremos las posibles vías de interpretación disponibles para este fenómeno, presentando los distintos enfoques en relación con los ejemplos anteriormente descritos y subrayando la complementariedad de muchas de estas propuestas interpretativas.

\section{REUTILIZACIÓN DE MATERIALES ANTIGUOS}

Dentro de este apartado podemos distinguir dos grandes categorías. En primer lugar, el reempleo de antiguos materiales de construcción (sillares, ladrillos, tegulas...), con esa misma función edilicia, en el nuevo edificio cristiano. Se trata generalmente de materiales romanos, cuyo reempleo es muy habitual en las iglesias altomedievales, especialmente entre los siglos VII y X (QUIRÓs \& FERNÁNDEZ 2001; CABALlERO \& UTRERO 2005; Utrero \& SASTRE 2012). En Galicia podemos citar los ejemplos de Santa María de Mixós o Santa Comba de Bande, ambas construidas en el período altomedieval con sillares romanos expoliados de algún yacimiento más o menos cercano (UTRERO 2006: 583, 587). También hay indicios de que otras iglesias gallegas como San Xiao de Fontefría (RIVAS 1972), Santa Mariña de Vilarnaz (RIVAS 2003) o San Xeao de Trebo (RAmIL \& PICOS 2002; RAMIL \& LÓPEZ 2003), en las que se reutilizan materiales de construcción romanos, pueden ser sucesoras de una edificación altomedieval en las que esos materiales romanos ya se encontraban reutilizados. Sin embargo, es necesario un estudio arqueológico en profundidad de estas iglesias que confirme o desmienta esta hipótesis.

El segundo grupo se refiere al reuso de antiguas piezas esculpidas y decoradas en edificios cristianos, una práctica muy habitual en Galicia, como han dejado claro diversos trabajos (CABAllero \& SÁNCHEZ 1990; CASTIÑEIRAS 1990; SASTRE 2011). Se trata en su mayor parte de aras romanas, aunque también hay capiteles, basas, fustes, epígrafes, estelas, e incluso relieves de finales de la Edad del Hierro. Su colocación puede haber sufrido alteraciones con el paso del tiempo, aunque las aras suelen documentarse en el entorno del ábside, funcionando como pies de altar (sobre todo en los casos en que se les ha practicado un loculus o cavidad en su parte superior para depositar las reliquias del santo al que está dedicado dicho altar) mientras que los capiteles pueden mantener la misma antigua función de elemento de sustentación o bien adquirir otras nuevas como pilas de agua bendita (para lo cual se vacía su extremo superior) o elementos constructivos y/o decorativos incrustados en los muros de la iglesia.

Como se ha dicho, existen muchos casos de iglesias que conservan restos antiguos en Galicia. A los 35 casos de reuso de materiales romanos en iglesias que hace ya 25 años incluyeron Luis Caballero y José C. Sánchez para el caso de Galicia dentro de su amplio listado de ejemplos de este fenómeno en la Península Ibérica (CABALlero \& SÁnchez 1990), y a los 20 nuevos ejemplos que aporta Isaac Sastre para esta zona en su reciente tesis doctoral (SASTRE 2009: 299-314) podemos añadir aquí, sin ninguna pretensión de exhaustividad, otros 39 casos más recopilados durante la preparación de este trabajo. Se trata de las piezas reutilizadas o conservadas en las iglesias de Santa María de Temes (DElGado GómEZ 1979; 1990; YZQUIERDO 1993: 56, 66; DELGADO GÓMEZ 1997; 1996-2006, VoL V: 14), San Martiño de Mondoñedo (CHAMOSO 1967; NúÑEZ RodRÍGUEZ 1978: 237-242; CASTIÑEIRAS 1990: 79-80; YZQUIERDO 1993: 134-137; DELGADO GÓMEZ 19962006, Vol VI: 189), Amiadoso (CASTIÑEIRAS 1990, RODRÍGUEZ COLMENERO 1993: 469, YZQUIERDO 1993: 123, 152; FARIÑA 1997), San Salvador de Lourenzá (CASTIÑEIRAS 1990: 81; YZQUIERDO 1993: 154), Santa Eulalia de Esperante (DELGADO GÓMEZ 1996-2006, VOL. I: 317-327; RODRÍGUEZ COLMENERO 2005: 44-46; ARMADA \& MARTíN 
2007: 130-131), Santa María Nai de Ourense (NÚÑEZ RODRÍGUEZ 1978: 161-168; CASTIÑEIRAS 1990: 79; YZQUIERDO 1993: 30; RODRÍGUEZ COLMENERO 1993: 335-339), San Vicente de Adro Vello (CARro Otero 1989: 90), Santa Baia de Portela (ARMADA, MARTín 2007: 129), San Mamede dos Mártores (NúÑEZ RodRÍGUEZ 1978: 67), Santiago de Amoexa (Sobrado 2010), San Sadurniño de Goiáns (GonZÁlez Millán 1997, Vidal Álvarez 2004), San Pedro de Queizás (Rodríguez LOVElle, LÓPEZ QuirogA 1991), Santa María de Dexo (SOTO ARIAS \& LESTÓN GÓMEZ 1992; VVAA 2013: 421), Santaia da Espenuca (VEIGA, SoBrINo 2012), Santa María de Serantes (VVAA 2013: 1159), San Vicente de Fervenzas (VVAA 2013: 473), Santa Olaia de Portorroibo (ARMADA PITA 2003: 380, ARMADA \& MARTín 2007: 139), San Román das Encrobas (Bonilla 2000), Santa Eulalia de Alto Xestoso (ARMAdA PITTA 2003: 386), San Pedro de Laroá (RodRíGUEZ COLMENERo 1985: 333), Nosa Señora do Xurés (Eguileta, Rodríguez \& Xusto 1991: 149), Santa María de Bascuas (Delgado Gómez 1996-2006, VOL. V: 252), San Pedro de Vilanova (DELGADo Gómez 1996-2006, VOL. IV: 250-253), San Cosme de Sésamo (VVAA 2013: 1165), San Lourenzo de Abeleda (RIVAS QUINTAS 1985: 350), Santa Eulalia de Lañas (ARMAdA 2003: 382), Santa Baia de Camba (VVAA 2012: 357), San Tomé de Nogueira, San Xoán de Seoane de Oleiros, San Martiño de Cores, Santa Comba de Louro, San Antón da Siota, San Sebastián de Formigueiros, Santa María de Abedes ${ }^{2}$, San Pedro de Baroña, Santa Eulalia de Atios, San Pedro de Cela, Santa María de Bermés y San Andrés de Lourizán ${ }^{3}$.

Es probable que la reutilización de esas piezas esculpidas antiguas en algunas o incluso en muchas de las 94 iglesias gallegas arriba referidas, haya tenido lugar ya en época altomedieval, en base a los paralelos que explicaremos a continuación $\mathrm{y}$ al hecho conocido de que las aras romanas constituyeron el pie de altar más habitual y difundido en el Noroeste de la Península Ibérica durante toda la Alta Edad Media (SASTRE 2009: 300-314). Sin embargo, en la gran mayoría de casos no tenemos pruebas arqueológicas claras que nos permitan saber en qué momento se produjo la reutilización de dicha pieza antigua. De hecho no podemos descartar ningún periodo ya que el reuso de materiales y piezas esculpidas antiguas ha sido una constante a lo largo de todo el período pleno y bajomedieval, moderno y hasta la actualidad (CASTIÑEIRAS 1990). Un ejemplo muy representativo es el caso de San Mamede de Urrós (Allariz), emplazada en un entorno arqueológico con enterramientos de época romana, y en cuyo altar se localizó un ara romana con loculus y dentro de él un relicario y una copia de un pergamino de consagración de la iglesia por el obispo de Ourense en 1147 (PÉREZ OUTEIRIÑo 1979). Es decir, parece muy probable que la reutilización como altar de esa ara se produjo en el s. XII. Pero también tenemos numerosos casos de reusos de piezas antiguas en tiempos más recientes, como sucede con el ara que está apoyada en el muro exterior de San Pedro de Laroá (Xinzo de Limia). Pese a que sabemos, por un documento, que esta iglesia se fundó en el s. IX, el ara fue colocada allí en el s. $\mathrm{XX}$, tras haberse encontrado semienterrada en una calle del pueblo, quizá en relación con la necrópolis tardorromana de A Rivela (RODRÍGUEZ COLMENERO 1985: 333).

Tras una revisión de toda la información disponible, tan solo hemos podido encontrar algún tipo de prueba del reuso de alguna pieza esculpida antigua durante el período altomedieval en Galicia en 9 casos. Estas pruebas consisten en relaciones estratigráficas, en epígrafes (con fecha o por el tipo de letra), en tipologías estilísticas o en la coherencia constructiva del edificio, aunque en ningún caso pueden tomarse como evidencias definitivas ${ }^{4}$.

En primer lugar hay que señalar el caso de la antigua iglesia de Santa Comba de Louro (Valga), en la que se localizó un fragmento de estela tardorromana con epígrafe que probablemente pueda datarse en el siglo IV y que pertenecería al asentamiento tardorromano sobre el que se asienta la iglesia. Esta estela, que todavía no parece cristiana, está reusada como zócalo del muro de la fachada de la iglesia altomedieval, concretamente ejerciendo de esquinal inferior de la puerta principal de la misma (Fig. 1). Por su posición estratigráfica podemos decir que esta pieza fue colocada en dicho lugar en el momento de construcción de la primera iglesia altomedieval, entre los siglos V-VIII, según los arqueólogos que la excavaron, y probablemente se encontraba enterrada o semienterrada, sin estar a la vista (TOMOS 2012).

En segundo lugar, hay que hablar de la pieza de mármol blanco decorada con bajorrelieves hallada en el pavimento de la iglesia de San Sadurniño de Goiáns (Porto do Son). Se trata de una pieza rectangular decorada con motivos simbólicos: dos cráteras, un templo, y diversos elementos naturales. En el centro presenta una inscripción en letra capital romana cuidada de la que solo se pueden leer algunas partes, aunque parece claro que se refiere a la edificación y consagración de una primitiva basílica cristiana:

${ }^{2}$ Estos siete últimos ejemplos se basan en apreciaciones y visitas del autor.

${ }^{3}$ Las aras localizadas en estas cinco iglesias se encuentran actualmente expuestas en el Museo arqueológico provincial de Pontevedra

${ }^{4} \mathrm{~A}$ estos casos cabría añadir una serie de aras romanas en iglesias, estudiadas por Isaac Sastre que aunque están descontextualizadas, poseen una serie de características como sus dimensiones, la existencia de un repicado en su parte superior y el tamaño del loculus, que permiten proponer que fueron reutilizadas como partes de altares en época altomedieval. Se trata de los casos del San Paio en Santiago de Compostela, Viloria, San Roque de Seavia, Vilar, San Pedro de Soandres y San Martiño de Meirás (SASTRE 2009: 299-314). 


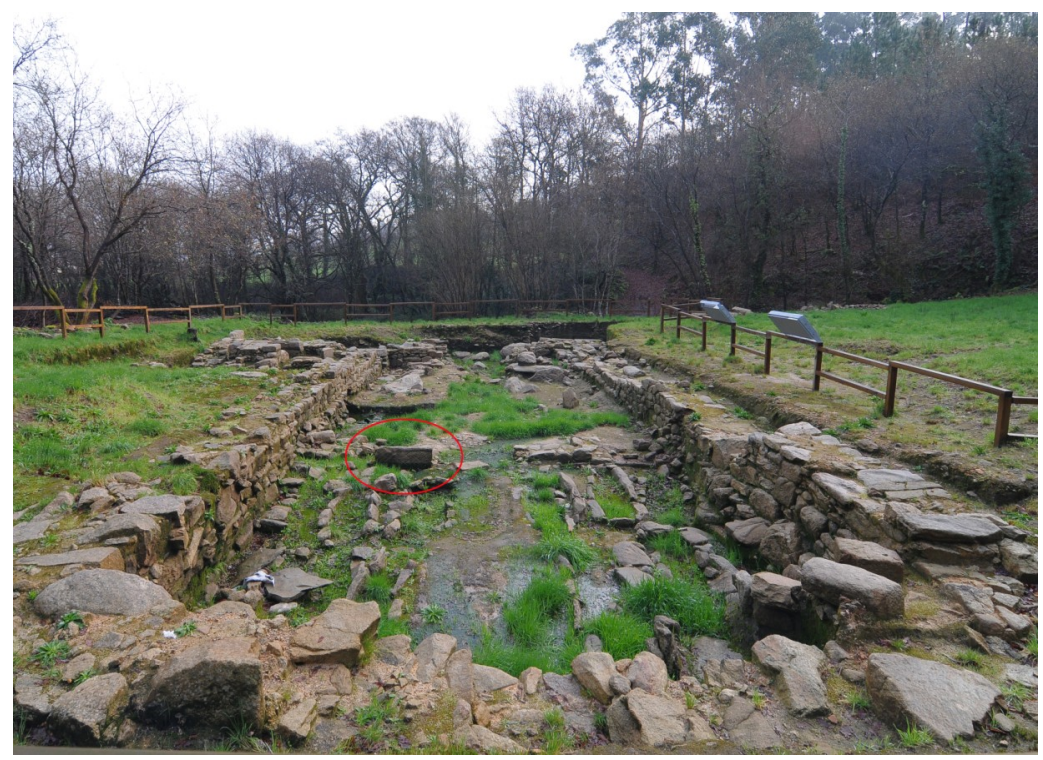

Fig. 1. Estela galaicorromana reutilizada en la parte inferior de la fachada de la antigua iglesia de Santa Comba de Louro (Valga). Fotografía realizada por Rebeca Blanco Rotea, en el marco del proyecto EMCHAHE.

Fig. 1. Roman stela reused in the foundation of the old church of Santa Comba de Louro (Valga).

Photograph by Rebeca Blanco Rotea, for the EMCHAHE project.

"... AEDIFICAVIT ET SACRAVIT... BASILICA XPO..." (GonZÁlez Millán 1997). Debido al contenido de dicho epígrafe, los primeros estudios consideraron que se trataba de una placa de consagración de una iglesia de segunda mitad del siglo VI (GONZÁlEZ MiLlán 1997). Sin embargo, nuevas investigaciones han demostrado que se trata de un frontal de sarcófago romano de primera mitad del s. V, probablemente traido del norte de Italia (VIDAL ÁlvAREZ 2004), al que se añadió posteriormente, en época altomedieval, dicha inscripción. Estaríamos, por tanto, ante el reuso de una pieza funeraria tardorromana para ser colocada en un lugar bien visible de una iglesia altomedieval, quizá encima de la puerta principal de la misma. No sabemos en qué fecha se produjo esta reutilización, pero tenemos algunos indicios. El edificio actual conserva vestigios en su fábrica de una construcción prerrománica de inicios del siglo $\mathrm{X}$ y de clara influencia del modelo compostelano (YZQUIERDO 1993: 86). Pero podemos pensar que en este lugar ya existía una iglesia desde tiempo atrás, ya que aparece mencionada en un documento del año 868 en el que se indica, además, que la iglesia pertenecía al obispo de Iria (LÓPEZ ALSINA 1988: 156). Según M. C. Díaz y Díaz (1993: 66) la passio y la advocación a San Saturnino se extienden en el siglo VII, y quizá en ese período podría datarse la primera iglesia en este lugar. También hay que señalar que en su entorno aparecieron restos de un mosaico, una basa y un capitel tardorromanos, así como una estela discoide, decorada con una cruz inscrita en un círculo (PÉREZ LosAdA 1991: 439). El hecho de que en el
868 esta iglesia estuviera en manos del obispo de Iria y de que, poco despues fuese objeto de una importante obra que sigue el modelo compostelano, sugiere la idea de que probablemente se trató de un expolio controlado por las autoridades.

Otro ejemplo de reutilización que se puede documentar en época altomedieval es el de la antigua capilla de San Adriao de Amiadoso (Allariz), actualmente transformada en un garaje. Entre los muros de este edificio aun se se aprecian restos de una fábrica prerrománica, que algunos autores databan en época visigoda (CASTIÑEIRAS 1990; RODRÍGUEZ COLMENERO 1993: 469) aunque actualmente se considera de época mozárabe, en torno al siglo X (YZQUIERDO 1993: 123, 152; FARIÑA 1997). Entre estos muros también se encontraban dos sillares graníticos con cruces asturianas con alfa y omega, así como una pilastra tallada en mármol en sus seis caras. Tres de las caras de esta pilastra de marmol habrían sido talladas en época tardorromana, en torno al siglo IV, y representan un motivo báquico con una vid surgiendo de una crátera así como decoraciones vegetales y probablemente formaba parte de un mausoleo funerario cristiano. Sin embargo, la pieza habría sido profundamente reformada en torno a inicios del X, cuando se ornamentarán otras tres caras, con relieves de personajes con túnica de dificil interpretación (Fig. 2), similares a los de San Juan de Camba o la pila de San Isidoro de León (FARIÑA 1997). De igual modo se localizó en el entorno de esta iglesia un capitel corintio romano tambien del siglo IV, parcialmente vaciado para servir de pila de agua bendita. 


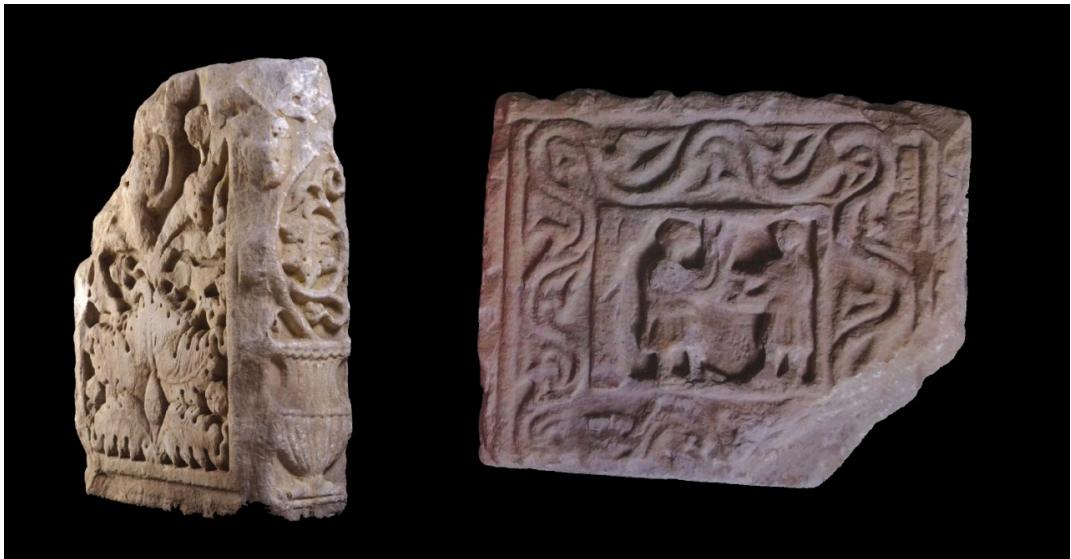

Fig. 2. Dos vistas del bloque de mármol con relieves procedentes de la antigua iglesia de San Adriao de Amiadoso (Allariz). En el lado izquierdo se puede apreciar la decoración de época romana, mientras que en el derecho se muestran los relieves realizados en época altomedieval, probablemente en torno al siglo X. Imagen elaborada a partir de las fotografías de la figura contenidas en CERES y en la obra de R. Yzquierdo (1993, p. 151).

Fig. 2.Two views of the marble carvings found in the old church of San Adriao de Amiadoso (Allariz). To the left side, the roman decoration; to the right, early medieval reliefs (probably 10th century). Photographs from CERES database and Yzquierdo 1993, p. 151.

Tambien se puede señalar el caso de la iglesia de Santa Mariña de Asadur (Maceda). En el altar de esta iglesia románica del siglo XII, se reutilizaba, como pie de altar, una lápida romana. Se trata de un bloque de forma cúbica sin molduras con una inscripción romana dedicada a un "duunviro" o cobrador de impuestos entre los "interamnicos". En uno de los lados de la cara superior se grabó una inscripción cristiana: +AELTARE y hay indicios de un posible "loculus" en la cara superior. Según los distintos autores que la han estudiado, la grafía de esta última inscripción corresponde a época altomedieval, probablemente entre los siglos IX-X, lo que nos indicaría que fue en este momento (si no antes) cuando se produjo su reutilización como parte del altar (SASTRE 2009: 325; CABALlERO \& SÁNCHEZ 1990: 475). También hay que señalar que aunque la fábrica de la iglesia actual corresponde principalmente al siglo XII, en la pared norte de la sacristía se conserva un bajorrelieve de granito que representa una crucifixión con una inscripción que dice "Jesús en la cruz", en letra visigótica y cuya datación oscila, según cada autor, entre los siglos VII y XI, así como la existencia de otra inscripción probablemente altomedieval en una laja de granito de uno de los altares laterales y las referencias a la aparición de restos de enterramientos romanos y medievales en el entorno inmediato de la iglesia (RIVAS QUINTAS 1985: 85, 242; RODRÍGUEZ COLMENERO; RODRÍGUEZ LOVELle 1991; RIVAS \& DELGADo 1991). Aunque no se trata de pruebas concluyentes, si parecen apoyar la existencia de un templo prerrománico anterior al actual en este lugar.

Otro caso de reuso que podemos constatar que se produjo en la alta edad media es el del ara de Suatorre (Baños de Molgas), a 1500 metros de la iglesia de Santa Eufemia de Ambía. Esta ara tiene un hueco para contener reliquias y una inscripción de época altomedieval sobre la antigua dedicatoria romana. Según el estudio de J. C. Rivas y E. Rivas (1989), la inscripción, que presenta un latín muy correcto, indica que está dedicada, en nombre de Dios, a Analso. Además, dicha inscripción se repite en las caras laterales del ara, con mucha mejor caligrafía, en unos trazos que recuerdan al epígrafe de consagración de Santa Eufemia de Ambía y que se pueden datar probablemente a mitad del s. IX (Fig. 3). Los autores del estudio plantean que este Analso sería un persona importante y querida en la comunidad, probablemente un obispo de Ourense (uno de los primeros tras la restauración de la sede, poco antes del primero conocido, Sebastiano, del 872-898), y que al morir, quizá a mitad del s. IX, la comunidad le dedicó esta deposición de reliquias y huesos de santo (RIVAS \& RIVAS 1989). Parece, por tanto, probable, que esta ara provenga de la iglesia de Santa Eufemia de Ambía, y que funcionase de pie de uno de los tres altares que tendría dicha iglesia, aunque no se puede descartar que perteneciese a otra iglesia del entorno, que, en todo caso, habría sido fundada por los mismos patrones.

El anterior caso nos sirve como apoyo para pensar que las dos aras romanas en la iglesia de Santa Eufemia de Ambía (Baños de Molgas) fueron reutilizadas en época altomedieval. Una de ellas funciona como base de altar, mientras que otra ejerce de columna de la ventana geminada del ábside principal de la iglesia (NÚÑEZ RODRÍGUEZ 1978: 211-221; YZQUIERDO 1993: 137-142). El hecho de que el ara hallada en el cercano lugar de Suatorre fuese reutilizada en el mismo momento de consagración de esta iglesia (como sabemos por el gran parecido del tipo de letras), en torno al siglo 


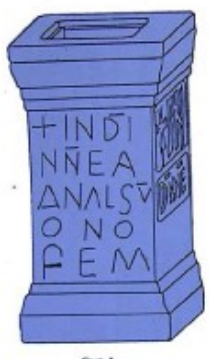

$\cos x$

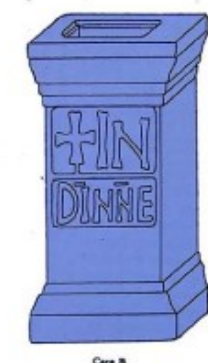

$\cos \left(\frac{10}{20}\right.$

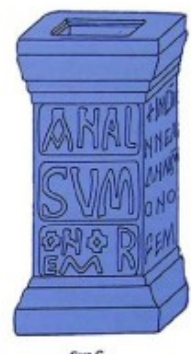

$\operatorname{cosc}$
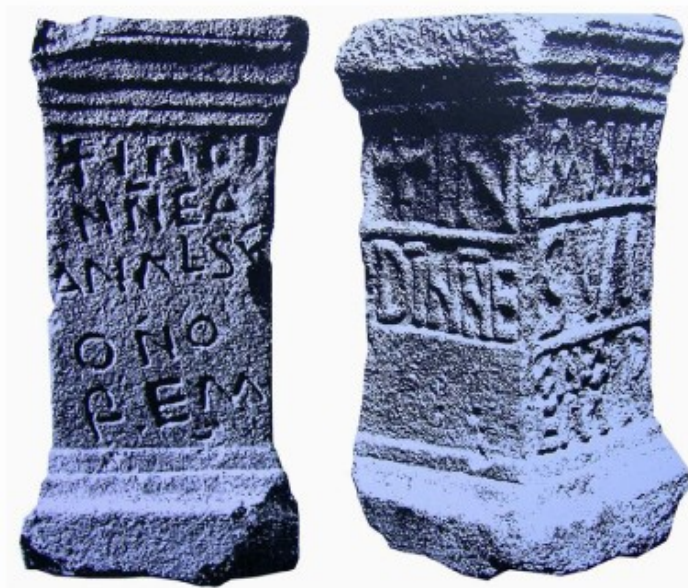

Fig. 3. Ara romana con inscripciones altomedievales hallada en Suatorre de Ambía (Baños de Molgas). Imagen tomada de Rivas, Rivas 1989, p. 129 y Sastre 2009, vol. 2, lámina CXXX).

Fig. 3. Roman ara with early medieval inscriptions found in Suatorre de Ambía (Baños de Molgas). Pictures from Rivas, Rivas 1989, p. 129 and Sastre 2009, vol. 2, figure CXXX.

IX, nos hace suponer que también en ese momento se produjo la reutilización de estas otras dos aras. Además, el mantenimiento de buena parte de la fábrica y estructura del edificio prerrománico hasta la actualidad, nos hace plantear que ambas aras deben provenir de dicha fase prerrománica, sin que haya demasiados argumentos para pensar en importantes reformas posteriores tanto del altar central como de la ventana (Fig. 4). Esto es también lo que han supuesto otros trabajos previos (CABALlERO \& SÁNCHEZ 1990; CASTIÑEIRAS 1990; SASTRE 2009). Hay que tener en cuenta que en la parte baja de la aldea de Santa Eufemia, en la que se emplaza la iglesia, existe una fuente con distintas tradiciones asociadas, y que probablemente en este lugar existió un lugar de culto romano a las ninfas, que estaría situado además a los pies de una via romana que pasaba por el lugar. En este sentido, es probable que hubiese mucha disposición de aras romanas en el lugar cuando se construyó la iglesia.

Un caso similar sería el de la iglesia prerrománica de Santa María de Mixós, del siglo X. En esta iglesia se constatan tres aras bajo la mesa de altar principal (parte de la cual parece la tapa de un sarcófago recortada) así como otra en el altar lateral. Aunque no hay pruebas directas, de nuevo

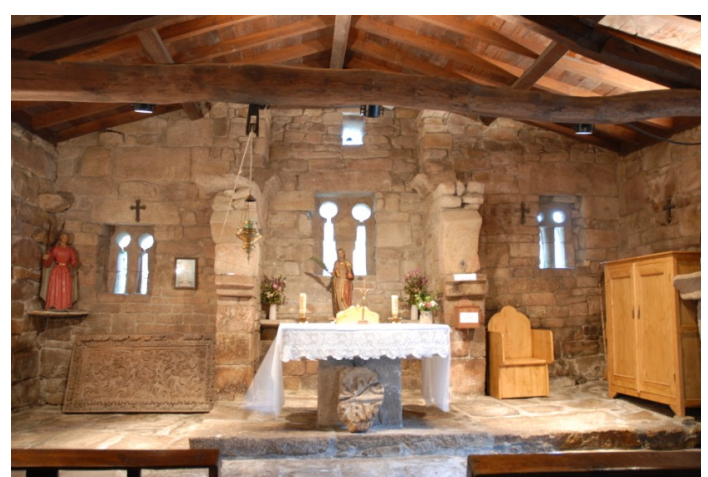

Fig. 4. Interior de la iglesia prerrománica de Santa Eufemia de Ambía. Fotografía realizada por Rebeca Blanco Rotea.

Fig. 4. Interior of the early medieval church of Santa Eufemia de Ambía. Photograph by Rebeca Blanco Rotea.

la conservación de gran parte de la fábrica prerrománica del edificio nos hace plantear que también a dicha fase pertenecen esas aras que funcionan de pie de altar, algo que también mantienen otros autores (CABALLERO \& SÁNCHEZ 1990: 475; CASTIÑEIRAS 1990; SASTRE 2009: 322-324). Por otro lado, como ya hemos señalado, parece probable que los sillares de esta iglesia sean romanos reutilizados (UTRERO 2006: 587).

Y lo mismo se puede decir de las piezas reutilizadas en Santa Comba de Bande (Bande), una de las iglesias prerrománicas más estudiadas y debatidas de la Península Ibérica, cuya datación se discute entre el siglo VII o el IX (RIVAS 1971: 81; NÚÑEZ RODRÍGUEZ 1978: 83-86; YZQUIERDO 1993: 44-52; RODRÍGUEZ COLMENERO 1993: 403; CABALlero, ARCE \& Utrero 2003, 2004; UtreRO 2006: 584). El arco de herradura que da entrada al ábside de esta iglesia está sostenido por cuatro columnas con capiteles distintos entre sí, y hay acuerdo entre los distintos autores en que al menos dos de ellos son capiteles reutilizados siendo en origen probablemente romanos (CABALLERO, ARCE \& UTRERO 2004: 311-312). Teniendo en cuenta los resultados del análisis estratigráfico del edificio se puede decir que los dos capiteles fueron reutilizados en el momento de construcción de la iglesia prerrománica que aun está en pié, sea ésta de cronología visigoda o mozárabe (CABALLERO, ARCE \& Utrero 2004). Por su parte, Rodríguez Colmenero va más lejos y considera que no solo estos dos capiteles, sino tambien sus columnas, la mesa de altar de mármol, el sarcófago también de mármol llamado de San Trocado que está en uno de los brazos del crucero, otro pie de altar y los vestigios de una escultura bifronte de granito que también están en el interior de la iglesia serían piezas reutilizadas de un antiguo mausoleo paleocristiano de los siglos IV-V (RodRíguez COLMENERO 1993: 403). Otra pieza romana que podría también haber sido reutilizada ya en época altomedieval en esta iglesia es un ara a la que se le han practicado dos loculus para depositar reliquias de dos santos y que probablemente sería el pie de altar 
principal (el actual parece moderno), ya que la iglesia se dedica desde finales del siglo IX a San Torcuato y Santa Comba (SASTRE 2009: 318-319). Además, al lado de la entrada, se encuentra un miliario reesculpido sirviendo como pila de agua bendita, y hay referencias a un ara a los lares viales con la misma función (RODRÍGUEZ COLMENERO et al. 2004: 529-531).

Finalmente hay que señalar el caso del sacófago tardorromano del monasterio de San Salvador de Lourenzá (Lourenzá). Sabemos a través de distintos documentos que este monasterio fue fundado por el conde Osorio Gutiérrez, primo del rey Ordoño, en el 968 y que dicho conde eligió como sepulcro un rico sarcófago romano de mármol blanco originalmente fabricado en Aquitania en el siglo V o VI (CASTIÑEIRAS 1990: 81; YZQUIERdO 1993: 154). Desconocemos cómo y cuando llegó este sarcófago hasta Lourenzá, pero como indica Manuel Castiñeiras, la reutilización de ricos sarcófagos romanos corresponde a una actitud frecuente entre los poderosos de los ss. IX-X (CASTIÑEIRAS 1990: 81).

\section{REUTILIZACIÓN DE ESTRUCTURAS Y EDI FICIOS}

Un segundo nivel de análisis, aunque profundamente ligado al anterior, lo constituye el del propio emplazamiento o lugar donde se construye la iglesia en el paisaje. En Galicia se documenta un alto número de iglesias que se superponen a yacimientos arqueológicos, especialmente de época romana (villas, necrópolis, posibles lugares de culto...), tal y como se ha explicado en otros trabajos (SÁNCHEZ PARDO 2012) y siguiendo una tendencia común a otras zonas de la Península Ibérica y Europa (Percival 1997; Bell 2005; Chavarria 2007). Nuevamente, podemos distinguir dos grandes grupos.

Por un lado, aquellos casos en los que hay constancia de una reutilización parcial o total de una edificación o estructura en alzado, como parte constituyente, visible y significativa, de la nueva iglesia. En la recopilación llevada a cabo para la elaboración de este trabajo, hemos podido constatar esta secuencia en 4 casos:

En primer lugar, la primitiva basílica de Santiago de Compostela, construida en la primera mitad del siglo IX bajo los auspicios de Alfonso II sobre los restos de una necrópolis tardorromana y tardoantigua (asociada a un antiguo asentamiento romano abandonado en torno al siglo $\mathrm{V}$ ), que había dejado de usarse en algún momento del siglo VII (PÉREZ LOSADA 2002: 302-318; SUÁREZ OTERO \& CAAmaño Gesto 2003). Como han mostrado los diferentes estudios sobre la misma, esta primera iglesia sería una obra pequeña de una sola nave, realizada en piedra del lugar y arcilla como argamasa, y usaría como ábside una tumba romana interpretada como el mausoleo de Santiago (NÚÑEZ RodRÍGUEZ 1978: 105-110; 1979; GUE-
RRA CAMPOS 1982; YZQUIERDO 1993: 73-85; SUAREZ OTERO 1999, 2004).

Lo mismo se puede decir de la basílica da Ascensión en Santa Mariña de Augas Santas (Allariz). Se trata de una iglesia del s. XIV (inconclusa) con una cripta debajo, que tendría su origen en una sauna de la Edad del Hierro. En un segundo momento, ya en la Alta Edad Media, quizá en relación con la expansión del culto a Santa Mariña y la leyenda de su martirio, se construye una iglesia a partir de este monumento con horno, usándolo como cabecera. Ya en los ss. X-XII, se cubre la estancia anterior con una bóveda (que imita a la del horno) y se hacen otras reformas. A finales del s. XIII e inicios del XIV, se construye por encima la basílica de la Ascensión, que no llegó a concluirse (BLANCO RoteA et al. 2009).

La iglesia altomedieval de Santa Eulalia de Bóveda (Lugo), también presenta claras evidencias de haberse construido sobre una edificación romana. Este emblemático -y problemático- monumento gallego alberga en su cripta abovedada una piscina y pinturas de estilo "romano". La interpretación más generalizada es que se trata de un inicial templo de culto pagano a las aguas (ninfeo) del siglo III; que a fines del IV se convertiría en cristiano (NúÑEZ RodRÍGUEZ 1978: 134-138; MONTENEGRO RÚA 2005). Sin embargo, los últimos estudios desde la arqueología de la arquitectura han mostrado la existencia de tres fases principales en la evolucion del edificio. Inicialmente existía un edificio abovedado y semienterrado para recoger el agua en la piscina que posiblemente ya constaba de dos pisos. En una segunda fase se hace la división del aula en tres naves, la decoración del interior con pinturas y placas decoradas, la reforma de la puerta y la posible modificación de la fachada. En una tercera fase se construye un segundo piso sobre el aula abovedada, quizá por un colapso del previo o por una reforma de esta (BLANCO ROTEA et al. 2009).

Otro caso muy interesante es el conjunto eclesiástico que se construye entre los siglos VIVII sobre el antiguo campamento romano de Cidadela (Sobrado dos Monxes). Se trata de dos iglesias, rodeadas de algunos enterramientos, que se superponen claramente a las estructuras romanas, y que se han interpretado como parte de un establecimiento monástico (COSTA \& VARELA 2011). Cabe destacar que las dos iglesias siguen la misma alineación que las antiguas estructuras romanas, a la vez que reusan gran parte de los muros y materiales constructivos romanos.

El segundo grupo se refiere a los casos en los que la iglesia se superpone a las anteriores estructuras romanas sin aparente mantenimiento de las mismas ni de su disposición formal. Se trata del grupo más numeroso, pero también el más problemático. A través de la documentación escrita y/ o la aparición de restos materiales descontextualizados o en excavaciones pre-estratigráficas, se 
puede suponer la superposición de numerosas iglesias gallegas de origen altomedieval sobre un yacimiento romano, como ocurre en Santa Eulalia de Tines, San Martiño de Mondoñedo, San Bartolomé de Rebordáns, Panxón, Santa María de Bretoña o San Xiao de Moraime (SÁNChEZ PARdo 2012). También en muchos de los casos destacados en el apartado anterior se puede intuir la cercanía de yacimientos de los que proceden los materiales reutilizados. Sin embargo hay muy pocos casos en los que se puede constatar estratigráficamente y con un mínimo de precisión, cuando y cómo se produjo esa amortización del asentamiento romano. Concretamente, consideramos que solo existe suficiente constancia arqueológica de ello en $6 \operatorname{casos}^{5}$ :
En primer lugar, la iglesia de época altomedieval documentada en la excavación del yacimiento de Adro Vello (O Grove). Según el director de la intervención, José Carro Otero, esta iglesia, de planta rectangular y un solo ábside tendría su origen posiblemente en torno al siglo VII, a partir de diversos hallazgos materiales (cruz osculatoria, placas decorativas de estilo "visigótico", etc). Como señala este autor, la iglesia se construye sobre una necrópolis, y partir de ese momento evolucionarán de manera asociada (Fig. 5). Por tanto, en este caso se puede constatar que la iglesia fue construida sobre un área de enterramiento, que a su vez se había creado, sobre las ruínas de un antiguo asentamiento romano tipo villa (CARRO OTERO 1987, 1989, 1991).

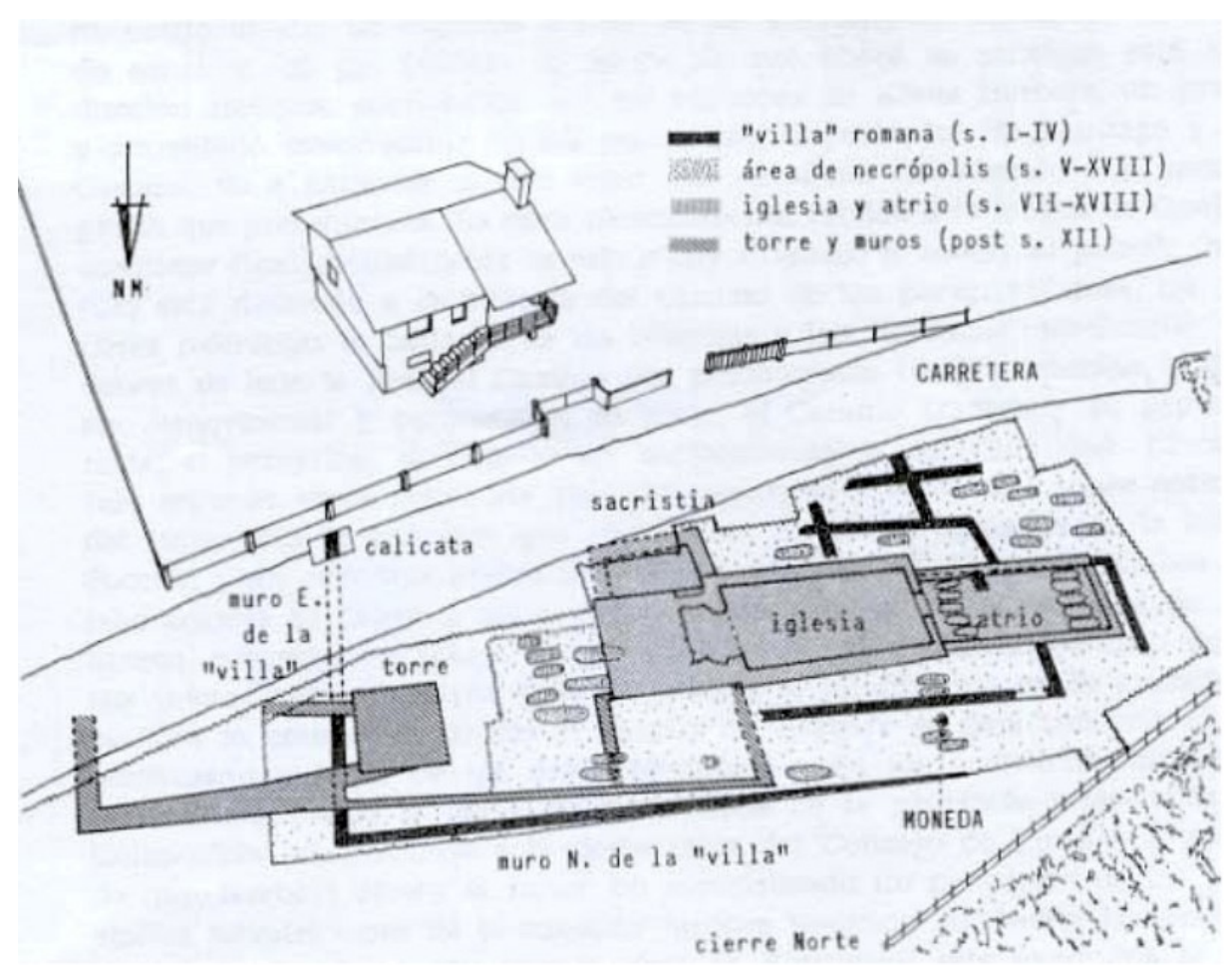

Fig. 5. Planta de las excavaciones en el yacimiento romano y medieval de Adro Vello (O Grove) (CARRO OTERO 1987, p. 577).

Fig. 5. Plan of the excavations in the roman and medieval site of Adro Vello (O Grove). Taken from Carro Otero 1987 , p. 577.

Una secuencia muy similar se ha constatado en el yacimiento de Eirexa Vella de Bares (Mañón) en el que la iglesia se construiría posiblemente en torno al siglo VII sobre una serie de enterramientos previos que a su vez amortizaban una villa y factoría tardorromana (RAMIL GONZÁLEZ 2000, 2003).

Otro caso bien conocido es el de la capilla de San Breixo de Ouvigo (Blancos), que según su excavador, tendría su origen en un inicial oratorio paleocristiano del siglo IV $-\mathrm{V}$, vinculado a un asentamiento tardorromano (Fig. 6). Este templo generaría una necrópolis a su alrededor y experimentaría una serie de reformas a lo largo de la alta edad media hasta su abandono en la Baja Edad Media (RodríGUEz COLMENERo 1985).

\footnotetext{
${ }^{5}$ Las excavaciones recientes en las iglesias altomedievales de San Martiño de Cores (Ponteceso), O Areal (Vigo) o San Vitor de Barxacova (Parada de Sil) probablemente puedan ofrecer más cronologías y estratigrafías de detalle para este tema, pero en el momento de redacción de este artículo, ninguna de ellas ha sido todavía publicada.
} 


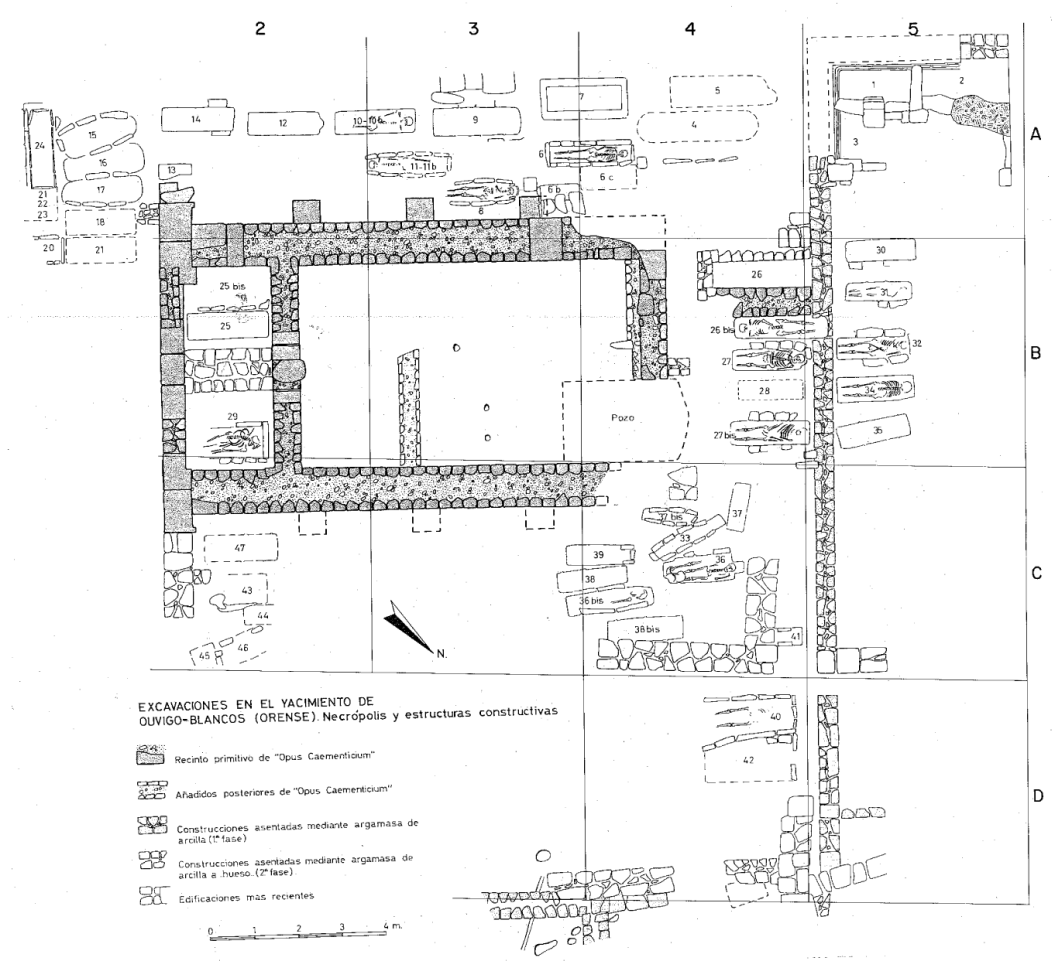

Fig. 6. Planta de las excavaciones en el yacimiento romano y medieval de Ouvigo (Os Blancos) (Rodríguez Colmenero 1985, p. 372).

Fig. 6. Plan of the excavations in the roman and medieval site of Ouvigo (Os Blancos). Taken from Rodríguez Colmenero 1985, p. 372.

En las excavaciones de la iglesia de Santa Mariña de Xinzo de Limia, realizadas en 19951996, se constató un nivel romano habitacional una domus urbana- de los ss. I-IV, seguido de una reutilización funeraria cristiana de la misma (ss. IV -VI), con tégulas, y posteriormente, tras un hiato temporal, una iglesia prerrománica de ss. IX-XI (XUSTO RodRíGUEZ 2000).

En el caso de Santa Comba de Louro (Valga), según sus excavadores, la iglesia se construiría en algún momento entre los siglos V y VIII amortizando un establecimiento tipo villa del siglo IV (Fig. 1). Se trataría de una pequeña iglesia basilical de planta rectangular acabada en una sencilla cabecera rectangular, quizá con una o dos habitaciones anexas para uso de algún eclesiástico o eremita, a la que estarían asociados cuatro enterramientos (dos tumbas excavadas en los restos del pavimento tardorromano, otra construida con paredes de piedras colocadas en posición horizontal cubiertas con una tapa y otra tumba hecha con piedras y reaprovechamiento de material latericio romano) (TOMOS 2012).

La capilla de San Xiao de Trebo (Cariño), muestra de nuevo una secuencia de un asentamiento tardorromano seguida de una iglesia. Aunque falta precisar mejor las cronologías, se puede hablar de una ocupación continuada del lugar desde ese momento hasta la actualidad. Se trataría originariamente de un establecimiento rural galaico- romano o pars rustica de una villa que evoluciona en el período altomedieval a una pequeña aldea rural de baja población y con economía de mera subsistencia en cuyos márgenes se situaría la iglesia, que aprovecha muchos de los materiales romanos (RAMIL \& PICOS 2002; RAMIL \& LÓPEZ 2003: 34).

En todos estos casos, la arqueología muestra un panorama mucho más complejo y dificil de interpretar que el del simple binomio continuidad o hiato entre el fin de la ocupación del asentamiento romano y la construcción de la iglesia. Se trata en todo caso, de interrogantes muy similares a los de otras zonas del sur de Europa (PARODI 1994: 116; ChAVARRÍA 2010, 2007: 143). Como hemos visto, existen dos grandes problemas. Por un lado, la escasez de estratigrafías y cronologías fiables que nos permitan saber cuando y sobre qué se construye exactamente la iglesia. Incluso en los pocos casos en los que se propone una cronología aproximada (siglo IV para Ouvigo, siglo VII para Adro Vello y Bares, y siglo IX-XI para Xinzo de Limia), no queda claro si existió una continuidad de uso del entorno hasta la construcción de la iglesia. Por otro lado, la dificultad de interpretar qué significa esa superposición. Como hemos visto, a menudo no existe una evolución directa entre el abandono de la villa y la construcción de la iglesia, sino una fase intermedia de transformación de la antigua villa romana en lugar de enterramiento. Es sobre esas necrópolis sobre la que se levanta, tiempo 
después, la iglesia altomedieval, sin que tampoco podamos descartar que ya hubiese en ellas un mausoleo o capilla funeraria paleocristiana que funcionase como primer lugar de culto (CHAVARRÍA 2010: 41).

\section{IGLESIAS, ÉLITES SOCIALES Y REUSO DEL PASADO EN LA GALICIA ALTOMEDIEVAL}

Una vez presentados los casos y contextos mejor conocidos de reempleo de materiales y estructuras, podemos pasar a reflexionar sobre la explicación y significados de este fenómeno, no sin antes recordar que aun estamos lejos de comprender bien cada contexto individual, por lo que las siguientes líneas no deben considerarse más que simples hipótesis e ideas de trabajo.

Como se ha señalado al inicio, existen distintas propuestas interpretativas sobre la reutilización en época altomedieval, dando lugar a un cierto debate entre autores que se inclinan por explicaciones meramente funcionales (aprovechamiento de materiales) y aquellos para los que el reuso posee una motivación ideológica o simbólica. En nuestra opinión, detrás de este fenómeno, que es complejo y multiforme, conviven diferentes casuísticas y múltiples motivaciones. En ese sentido, compartimos la idea de Bryan Ward-Perkins de que explicaciones pragmáticas y simbólicas no son necesariamente excluyentes y pueden convivir al menos en algunos casos (WARD-PERKINS 1999). Con el objetivo de mostrar la convivencia de estos distintos planos, vamos a articular nuestra exposición a través de varios niveles explicativos graduales, que van desde el plano más funcional al más simbólico.

\subsection{El factor práctico. Técnicas constructivas, reutilización y su coste económico}

Como han señalado diversos autores, la reutilización de material antiguo es una práctica común en las construcciones de gran parte del Occidente tardoantiguo y altomedieval debido a razones principalmente prácticas, ya que en este período se constata la práctica desaparición de la producción de sillería y técnicas de cantería en este período (Quirós, FERnÁNDEZ 2001; CABALLERO \& UTRERO 2005). Se trata de aprovechar los materiales antiguos que estaban al alcance, principalmente de antiguas estructuras romanas, como material de construcción o de decoración de buena calidad.

Esta actitud está presente en muchos de los casos anteriormente descritos: el reuso de sillares romanos para la construcción de iglesias como Santa Comba de Bande o Santa María de Mixós, la utilización (con pequeños ajustes) de aras romanas como pies de altar dado que la forma y medidas las hacen idóneas para ello, el aprovechamiento de los muros del antiguo campamento romano, en disposición Este-Oeste, para levantar las dos iglesias tardoantiguas en Cidadela, y un largo etcétera de explicaciones debidas al aprovechamiento práctico y funcional de todos aquellos materiales y estructuras antiguas.

Sin embargo, frente a ideas de pobreza o marginalidad relacionadas con este fenómeno, hay que señalar que el empleo de materiales de expolio para construir edificios en la alta edad media es una parte más de una cadena técnica, y como tal requiere personal y medios adecuados, pudiendo llegar a ser altamente costoso (DoMINGO 2009: 799; UtRERO \& SASTRE 2012). En ese sentido, y a través de paralelos de otras zonas de Europa, sabemos que durante la tardoantigüedad y la alta edad media existía un claro control de los spolia (y los yacimientos de los que estos proceden) por parte de las élites dirigentes (BRENK 1987; CHAVARRÍA 2009: 108-109). Al margen de la interpretación, pragmática o simbólica, del reuso de materiales y yacimientos antiguos en este período, no parece que se pueda hablar de un mero saqueo de las ruinas por parte de cualquier persona, ni mucho menos de prácticas de grupos empobrecidos o marginales. Al contrario, además del posible mantenimiento y/o concentración de la propiedad de los antiguos edificios romanos por parte de obispos, aristocracias laicas y reyes, el expolio de materiales antiguos constituye una actividad que requiere unas técnicas y especialistas específicos, y que a menudo podía ser altamente compleja (EATON 2000: 132-136; UTRERO \& SASTRE 2012; DOMINGO 2009: 799).

En el caso de Galicia, sin descartar otros posibles actores, tenemos varias evidencias de la acción de los obispos detrás del reuso de materiales antiguos en las iglesias. En primer lugar, sabemos por los concilios de la época que solo los obispos podían consagrar las iglesias, y esto es lo que vemos, ya en un momento posterior, en el caso antes mencionado de San Mamede de Urrós, en 1147, cuando es la autoridad del obispo de Ourense la que consagra las reliquias y controla la reutilización de un ara romana para albergarlas. También es interesante destacar que la mayor parte de las iglesias que reusan materiales antiguos se sitúan en zonas "centrales", cerca de vías de comunicación y de núcleos episcopales principales, y en ese sentido estarían bien controladas por los obispos. Tampoco parece casualidad que al menos tres de ellas: Santaia de Tines, San Sadurniño de Goiáns y A Espenuca aparezcan en listado de iglesias propias que pertenecían al obispo de Iria en el año 868 (LÓPEZ ALSINA 1988: 156), lo que de nuevo indica que en efecto son obispos y altas jerarquias los que controlan esos spolia.

\subsection{La estética y el prestigio de las antigüeda des como bien suntuario}

Un segundo plano de interpretación, que podríamos considerar intermedio entre intepretaciones funcionalistas y aquellas simbólicas, del uso de spolia y estructuras antiguas por parte de los 
constructores de iglesias en la alta edad media, se centra en el evidente valor estético y suntuario de las mismas. Sin entrar aquí en el ámbito de las posibles reinterpretaciones o reinvenciones del pasado que el reuso permite, parece claro que la propia posesión de estas piezas o apropiación de estructuras antiguas concedía un plus de prestigio al fundador de una iglesia. Su capacidad (económica y socio-politica, como hemos visto) de conseguir dichos materiales antiguos y exhibirlos sería visto como un acto de prestigio social. Se trata en cierto modo de una actitud paralelizable, salvando, obviamente, muchas distancias, al moderno coleccionismo de antiguedades (ARAGUAS 2007).

De este modo podemos entender la reutilización de la antigua tapa de sarcófago de la iglesia de San Sadurniño de Goiáns como placa para conmemorar la consagración de la iglesia en algún momento indeterminado de la alta edad media. Esta pieza de mármol, ricamente decorada, constituía probablemente un material poco común en la Galicia altomedieval, y entre las razones de su elección como soporte de la inscripción de consagración de la iglesia (y no cualquier otra pieza), debió tener que ver su evidente riqueza y calidad. Lo mismo se puede decir de la reutilización del sarcófago de mármol tardorromano por parte del conde Osorio en el siglo X en su monasterio de Lourenzá. El carácter suntuario y excepcional de esta pieza otorga sin duda un gran prestigio a este aristócrata a la hora de elegirlo como lugar de inhumación, como hacían otras altas élites de su momento, como Fernán González y Fernándo Ansúrez que también habían reaprovechado otros sepulcros (MORALEJO 2004).

Pero sin duda uno de los mejores ejemplos de este valor estético y suntuario lo encontramos en los mármoles romanos que adornaban la desaparecida basílica prerrománica de Alfonso III en Santiago de Compostela. Sabemos a través del documento del Acta de Consagración de la basílica del año 899 que estos mármoles fueron mandados traer por el monarca desde la ciudad de Coria, en Extremadura (a los que a su vez habían llegado por mar, quizá desde Italia u otro punto del Mediterráneo). Alfonso III quiso expresamente que esos mármoles, que habían adornado "bellísimas casas" fuesen llevados a su nueva iglesia. Pese a que el documento fue gravemente alterado en el siglo XII, parece que la realidad de este pasaje merece fiabilidad (LÓPEZ PEREIRA 1993). Se trataba, pues, de materiales excepcionales y estéticamente reconocidos en su momento, y de nuevo, comprobamos cómo solo las más altas élites del momento tenían acceso al reuso de los mismos.

\subsection{El reuso del pasado como estrategia ideoló gica de legitimación}

Como han señalado diversos autores, el pasado, sobre todo el romano, constituía en la alta edad media una base muy poderosa para la legitimación social (BRADLEY 1987, 1993: 114-129; INNES 2000; EFFros 2001). En este sentido, la reutilización de materiales y estructuras antiguas altomedievales en iglesias podría esconder, además de un valor práctico y estético, una verdadera intencionalidad simbólica de apropiación y manipulación de la capacidad legitimadora del pasado (BRENK 1987; EATON 2000; Bell 2005; Araguas 2007; DOMINGO MAGAÑA 2009: 801).

A la hora de aplicar este tipo de interpretación al registro material disponible en Galicia, encontramos dos grandes problemas, que en gran parte son comunes a los de otras zonas de Europa.

Por un lado, el mero hecho de que los factores simbólicos e ideológicos son mucho más dificiles de detectar o interpretar arqueológicamente que las motivaciones pragmáticas o funcionales. Entramos de este modo en un campo ligado a la perspectiva de trabajo de cada autor. Así, por ejemplo, algunos autores consideran que el reuso de sillares, ladrillos y otros materiales de construcción en una iglesia altomedieval también llevaba aparejada la utilización del potencial simbólico de un antiguo edificio romano, "recubriendo" la nueva iglesia del antiguo prestigio que aquel poseía (EATON 2000: 100, 132; BELL 2005: 132-136). Uno de los argumentos en los que se basa esta idea es que el gasto en el transporte de dicho material desde lejos a menudo era superior al de su creación ex novo. Se trata de una idea interesante, que sin embargo no tiene en cuenta el contexto tecnológico y la inexistencia o escasez en este período de talleres artesanos capaces de elaborar materiales de cantería nuevos de suficiente calidad. Este problema podríamos aplicarlo a los casos ya mencionados de Santa Comba de Bande o Santa María de Mixós. Pero también se observan problemas similares en la superposición de iglesias sobre yacimientos antiguos, como sucede, por ejemplo con las iglesias tardoantiguas levantadas en el antiguo campamento romano de Cidadela: ¿existe una intención de apropiación del prestigo o valor del antiguo lugar de poder romano o se trata de un mero reaprovechamiento de materiales y estructuras visibles, que además estaban ya adecuadamente orientados para edificar una iglesia? No podemos asegurar cual de las dos explicaciones es la correcta, aunque parece probable que ambas sean complementarias.

Por otro lado, aunque muy ligado a lo anterior, encontramos el problema de la falta de información sobre la evolución del uso y del contexto social de cada yacimiento. Esto nos impide saber si nos encontramos ante la reutilización de espacios abandonados hacía décadas o siglos y que tenían un valor simbólico, o ante la continuidad de uso de un lugar de reunión, culto y/o enterramiento ya establecido. Un ejemplo lo encontramos en los capiteles y piezas con bajorrelieves de época tardorromana o sueva (ss. IV-VI) y que por tanto pertenecían a menudo ya en origen a una construcción 
cristiana. En este sentido, sería factible que hubiese existido un oratorio, una capilla funeraria, $u$ otro tipo de lugar de culto en uso hasta la construcción de la iglesia altomedieval que simplemente reaprovecha algunos de los elementos de aquel edificio anterior. Así, no se trataría tanto de un reuso del pasado como de un reaprovechamiento práctico y quizá suntuario de elementos de una iglesia anterior. También sería necesario conocer si existe continuidad en la propiedad del lugar entre la familia de los posesores de la antigua villa y la de los fundadores de la iglesia. Por último, frente a ideas tradicionalmente asumidas (RIVAS 1971: 77), no podemos asociar directamente la presencia de un ara romana en la iglesia con la cristianización de un lugar de culto precristiano. Como ya hemos señalado, las aras romanas constituyen el modelo de pie de altar más difundido e importante en el Noroeste de la Península Ibérica entre los siglos VI y XI (SASTRE 2009: 138-143) y no es descartable que existiese un circuito de transporte y suministro de estas aras durante todo este período, con indepencia de su procedencia y significado previo (UTRERO \& SASTRE 2012).

Pese a todo ello, el apoyo de los textos de la época nos ayuda a confirmar que en diversos casos sí existió una clara intencionalidad ideológica o simbólica. Como han señalado algunos autores, la interpretación del pasado material, es decir, de un antiguo monumento o resto, en la Alta adad Media no la podía hacer cualquiera, sino que se trata siempre de personalidades destacadas: obispos, viudas consagradas, nobles, judíos conversos, etc que actuan por inspiración divina, lo que les confiere el "monopolio" de la relación con Dios y los santos (EFFros 2001; CASTillo Maldonado 2004). Esto es lo que ocurre en Galicia con la inventio de la tumba del apostol Santiago a inicios del siglo IX. La interpretación de una antigua tumba romana como los restos del apostol fue avalada por el obispo de Iria, en medio de un contexto político fuertemente favorable a dicha identificación (LÓPEZ ALSINA 1988: 111 -126; DíAZ Y DíAZ 1991: 166). Es el obispo quien desde el inicio, autoriza e interpreta el hallazgo y significado de esos restos arqueológicos. Sabemos que estas "inventio" de reliquias debieron ser mucho más abundantes de lo que las fuentes conservadas nos transmiten (CASTILLO MALDONADO 2004) y por ello no sería descartable que algunas de las iglesias fundadas sobre yacimientos o necrópolis romanas respondan a esas inventio, ya que solía tratarse de "martires" tardorromanos, de los ss. III-IV.

En este sentido, es en los siglos IX-X cuando tenemos indicios suficientes como para hablar de la aparición de una verdadera ideología del pasado, con sus correspondientes estrategias de reutilización del mismo, en el Noroeste peninsular, en el contexto de expansión del reino astur-leonés y la necesidad de legitimar el proceso de "repoblación" o reorganización política que se experimenta esta zona entre los siglos IX-X (CASTIÑEIRAS 1990). Es en este escenario cuando se produciría un auge especial del reuso simbólico del pasado con valor legitimador, emulando a través del neovisigotismo la práctica carolingia de legitimación través del pasado romano (ARAGUAS 2007, DOMINGO MAGAÑA 2009: 801).

Aquí es interesante destacar que en Galicia, la cantidad y la densidad de evidencias de uso de spolia en los siglos IX-X parece muy superior al propio caso de Asturias, germen de la monarquía astur. Como ha señalado recientemente Chris Wickham, en Asturias en este período se constata un bajo uso de spolia en comparacion con otras zonas de Europa, quizá debido a de la escasez de spolia de buena calidad y a una actitud más independiente con respecto a la carga del pasado en el Norte de España, aunque reconoce que esos restos serían una paleta de motivos disponibles para representar elitismo (WICKHAM 2012: 477). Estos spolia solo aparecería en aquellas construcciones en las que hay certeza de la promoción real (QuiRós \& FERNÁNDEZ 012: 39). En Galicia las élites del momento encontraron un espacio y un repertorio arqueológico mucho más propicio y adecuado para legitimarse a través del pasado.

En este sentido, una hipótesis que podemos plantear a partir de los datos analizados, es que algunos de los constructores o fundadores de esas iglesias altomedievales, al igual que los redactores de las crónicas, poseían un cierto conocimiento "histórico-arqueológico", y comprendían, obviamente dentro de su mentalidad y cosmovisión, qué tipo de materiales o lugares del pasado estaban reusando e incluso su cronología aproximada. Esto implicaría una intencionalidad, consciente y diferenciadora, del reuso, e incluso nos permite hablar de una "arqueología en la alta edad media", en la que las élites sociales buscaban, seleccionaban e interpretaban los restos del pasado para utilizarlos en su propio presente (EFFROS 2001).

\section{CONCLUSIONES}

En las páginas anteriores hemos podido comprobar la complejidad y problemática que encierra el estudio de la reutilización de materiales y estructuras en las iglesias altomedievales. En este sentido, una primera conclusión es la necesidad de avanzar en la obtención de mejores y más precisos contextos arqueológicos en estos edificios para poder comprender mejor los detalles de cada reutilización, ya que de ellos depende no solo la atribución cronológica de esa reutilización sino, como hemos visto, interpretaciones muy diferentes entre sí para la misma.

En segundo lugar, y pese a esta problemática, es importante subrayar la importante extensión y densidad del reuso de materiales y estructuras en las iglesias altomedievales gallegas. A falta de 
datos cuantitativos, nos atrevemos a señalar que se trata de una de las zonas de la Península Ibérica donde el reuso del pasado, especialmente el romano, fue más importante o necesario para los constructores de las iglesias durante la Alta Edad Media. A nivel cronológico, y a partir de los datos disponibles, se puede decir que aunque el reuso de elementos y lugares antiguos ya se constata en Galicia entre los siglos VI-VIII, es sobre todo en los siglos IX-X cuando no solo tenemos un mayor número de evidencias de este fenómeno sino que dichas evidencias son más claras y significativas como sucede en los casos de Lourenzá, Ambía, Bande o Amiadoso. En todo caso, hay que recordar que se trata de un fenómeno que se prolonga en el tiempo y que seguirá produciéndose durante los siglos siguientes (CASTIÑEIRAS 1990).

En tercer lugar, no parece que el reuso deba considerarse sin más como un indicio de marginalidad o debilidad económica. Al contrario, son precisamente las élites sociales las que aparecen más vinculadas al control de los restos materiales del pasado en la Galicia altomedieval. Esto puede deberse a su propiedad sobre los mismos, su capacidad económica para costear su desmantelamiento, traslado y modificación, o a su interés en su potencial legitimador a nivel social. Concretamente, aunque las evidencias todavía son muy limitadas, hay indicios para pensar que los obispos ejercieron un especial control sobre los yacimientos y spolia durante este período.

En ese sentido, puede ser interesante, como hipótesis de trabajo a desarrollar en futuras investigaciones, el utilizar el reuso de piezas y lugares destacados como indicadores de la intervención de aristocracias y altas élites sociales en la construcción de una iglesia. Por un lado, al igual que en el citado caso de Asturias (DOMINGO MAGAÑA 2009: 801; QUIRÓS, FERNÁNDEZ 2012: 39), muchas de las iglesias gallegas altomedievales en las que se produce una reutilización de materiales o solares antiguos son especialmente monumentales, como los casos de Santa Eulalia de Bóveda, Santa Comba de Bande, Santa María de Mixós y Santa Eufemia de Ambía. Por otro lado, parece posible que algunos de los materiales romanos reutilizados fuesen traidos de lejos precisamente en el período altomedieval. Este podría ser el caso de las piezas importadas de mármol blanco, que no existe en Galicia, de San Sadurniño de Goiáns, la basílica compostelana de Alfonso III, Lourenzá o Santa Comba de Bande. Aunque tradicionalmente se suele suponer que dichos materiales habían llegado a Galicia ya en época romana, no se puede descartar en absoluto su traslado a la región en el período altomedieval para su reutilización específica en las iglesias que se estaban construyendo o reconstruyendo en ese momento.

Por último, con respecto a las posibles interpretaciones de este fenómeno, hay que señalar que es necesario estudiar cada caso individualmente, ya que parece probable que existan diferentes casuísticas. Sea como sea, también hemos podido comprobar como en numerosos ejemplos pueden convivir interpretaciones pragmáticas con otras más simbólicas. Pese a que es evidente la abundante reutilización de piezas y yacimientos como materiales y canteras de construcción, también parece aceptado que durante el período visigodo y astur existió en la Península Ibérica, al igual que en otras zonas de Europa, una necesidad de legitimación del poder en base al antiguo mundo romano. Es necesario, por tanto, avanzar más allá del debate entre dos posturas opuestas, para incorporar escenarios interpretativos más complejos. Pese a las numerosas limitaciones que todavía encuentra la investigación, es evidente que se trata de un campo de gran interés para el conocimiento de las sociedades altomedievales del norte de la Península Ibérica.

\section{BIBLIOGRAFÍA}

Araguas, P. 2007. Spolia/Contrefaçon, deus modalités d'appropiation du passé, pour quelles élites? Hortus Artium Medievalium, 13/2: 347-358.

Armada Pita, X. L. 2003. El culto a Santa Eulalia y la cristianización de Gallaecia: algunos testimonios arqueológicos. Habis, 34: 365-388.

ARMADA, X. L.; MARTín, M. 2007. Novidades sobre o culto a Sta. Baia/Eulalia e a Arqueoloxía paleocristiá do NO. peninsular. Larouco, 4: 123-139.

BeLl, T. 2005. The Religious Reuse of Roman Structures in Early Medieval England. Oxford, Archaeopress.

Blanco-Rotea, R.; MañanA-Borrazas, P.; MATOFresÁn, C.; RodrígueZ-Costas, A. 2009. La Basílica de la Ascensión y Os Fornos (Allariz, Ourense), Revista Aquae Flaviae, 41: 467-477.

Blanco-Rotea, R.; Benavides García, R.; SANJurjo SÁNCHEZ, J.; FERnÁNDEZ MOSQUERA, D. 2009. Evolución constructiva de Santa Eulalia de Bóveda (Lugo, Galicia), Arqueología de la Arquitectura, 6: 149-198.

BoniLla, A. 2000. Trabajos arqueológicos en la Iglesia de S. Román das Encrobas (Cerceda, La Coruña), Brigantium, 12: 247-251.

BRADLEY, R. 1987. Time regained: the creation of continuity, Journal of the British Archaeological Association, 140: 1-17.

BRADLEY, R. 1993. Altering the Earth. The origins of monuments in Britain and continental Europe. Edinburgh.

BRENK, B. 1987. Spolia from Constantine to Charlemagne: Aesthetics versus Ideology, Dumbarton Oaks $\mathrm{Pa}$ pers, 41: 103-109.

Caballero, L.; Arce, F.; Utrero, M. A. 2003. Santa Comba de Bande (Orense). Arquitectura y documentación escrita, Arqueología de la Arquitectura, 2: 69-73.

CABallero, L.; ArCE, F.; Utrero, M. A. 2004. La iglesia de San Torcuato de Santa Comba de Bande (Orense). Arqueología de la Arquitectura, Archivo Español de Arqueología, 77: 273-318. 
Caballero, L.; SÁnCheZ, J. C. 1990. Reutilización de material romano en edificios de culto cristiano, Antigüedad y cristianismo, VII: 431-485.

CABAllero, L.; Utrero, M. A. 2005. Una aproximación a las técnicas constructivas de la Alta Edad Media en la Península Ibérica. Entre visigodos y omeyas, Arqueología de la Arquitectura, 4: 169-192.

Carro Otero, J. 1987. Moneda del rey D. Fernando II de Galicia-León y "ceca" compostelana, con el tema de la "Traslación" del cuerpo del Apostol Santiago (1157-1188), Compostellanum XXXII, n. 3-4: 575 594.

Carro Otero, J. 1989. Xacemento antropo-arqueolóxico de Adro Vello (San Vicenzo de O Grove, Pontevedra). In: VVAA, Arqueoloxía/Informes 1, campaña de 1987, Santiago de Compostela: 86-92.

Carro Otero, J. 1991. Adro Vello (S. Vicenzo do Grove, Pontevedra). In: VVAA, Arqueoloxía/Informes 2, campaña de 1988, Santiago de Compostela: 93-99.

CAstillo Maldonado, P. 2004. "Inventiones reliqviarvm" en la Hispania tardoantigua: análisis de sus actores", Polis: Revista de ideas y formas politicas de antigüedad clásica, 16: 33-60.

CASTIÑEIRAS, M. A. 1990. La reutilización de piezas romanas y medievales en Galicia, Brigantium, 6: 77-90.

Chamoso, M. 1967. Sobre necrópolis de época sueva en Galicia. In: $1^{a}$ y $2^{a}$ asambleas lusitano-gallega, Madrid: 93-96.

Chavarría, A. 2007. El final de las villae en Hispania (siglos IV-VII d. C.), Turnhout, Brepols.

CHAVARRÍA, A. 2010. Alcune osservazioni sulle chiese rurali di epoca tardo antica: documentazione testuale e fonti archeologiche. In: Galetti, P. (coord.), La tarda antichità tra fonti scritte e archeologiche, Bologna, Clueb: $35-54$

Costa, J.; VArela, D. 2011. A Cidadela después de Roma: introducción al estudio del yacimiento y su entorno durante el periodo medieval, Gallaecia, 30: 181194.

Cutler, A. 1999. Reuse or use? Theoretical and practical attitudes toward objects in the Early Middle Ages. In: Ideologie e pratiche del reimpiego nell'alto Medioevo. Atti delle settimane di Studio del Centro Italiano di Studi sull'Alto Medioevo. XLVI, Spoleto, Centro Italiano di Studi sull'Alto Medioevo: 1055-1079.

Delgado Gómez, J. 1979. El complejo de Temes. ¿Un monumento paleocristiano?. In: Actas del XV Congreso Nacional de Arqueología, Zaragoza: 1143-1154.

DELGADO GómEZ, J. 1990. El primer arte cristiano en la provincia de Lugo, IV Coloquio Galaico-Miñoto. Resumes das comunicacións presentadas, Lugo: 163-167.

Delgado Gómez, J. 1996-2006. El románico de Lugo y su provincia, A Coruña, Edinosa.

Delgado GómeZ, J. 1997. O conxunto paleocristián de Temes. In: García Iglesias, X. M. (ed.), Galicia castrexa e romana, Santiago de Compostela, Xunta de Galicia: 298-303.

DÍAZ Y DíAZ, M. C. 1993. Galecia visigoda. In: Vázquez Varela, J. M., O feito relixioso na historia de Galicia. Santiago de Compostela, Asociación Galega de Historiadores: 59-70.
Domingo MagañA, J. 2009. La reutilización de material decorativo clásico durante la Tardoantigüedad y el altomedioevo en Cataluña, Butlletí arqueològic 32 , Tarragona: 795-848.

EAton, T. 2000. Plundering the past. Roman stonework in Medieval Britain, Stroud, Tempus.

EFFros, B. 2001. Monuments and memory: repossesing ancient remains in early medieval Gaul. In: De Jong, M., Theuws, F., Van Rhijn, C. (eds.) Topographies of power in the early Middle Ages, Leiden, Brill: 93-118.

EguiletA, J. M.; RodríGueZ, C.; Xusto, M. 1991. Arqueoloxía na Baixa Limia. O encoro de Lindoso e o seu entorno: Lobios (Ourense), Arqueoloxía/Informes 2, campaña de 1988, Santiago de Compostela: 139 156.

FARIÑA, F. 1997. Amiadoso. In: García Iglesias, X. M. (ed.), Galicia castrexa e romana, Santiago de Compostela, Xunta de Galicia: 313-317.

Fuentes DomíngueZ, A. 2000. Las termas en la Antigüedad Tardía: reconversión, amortización, desaparición. El caso hispano. In: Fernández Ochoa, C., García Entero, V. (eds.) Termas romanas en el Occidente del Imperio, Gijón, Ayuntamiento de Gijón: 135-145.

GonZÁlez MilláN, A. J. 1997. El sarcófago paleocristiano de Portosín. In: García Iglesias, X. M. (ed.), Galicia románica e gótica, Santiago de Compostela, Xunta de Galicia Santiago de Compostela: 32-37.

Greenhalgh, M. 1989. The survival of Roman Antiquities in the Middle Ages, London: Duckworth.

GUERRA CAMPOS, J. 1982. Exploraciones arqueológicas en torno al sepulcro del Apóstol Santiago, Santiago de Compostela, Cabildo de la Catedral de Santiago de Compostela.

INNES, M. 2000. Introduction: using the past, interpreting the present, influencing the future, The uses of the past in the Early Middle Ages, Cambridge, Cambridge University Press: 1-8.

JimeneZ, J. A.; SALES, J. 2004. Termas e iglesias durante la Antigüedad Tardía: ¿reutilización arquitectónica o conflicto religioso? Algunos ejemplos hispanos, Antigüedad y cristianismo XXI, Murcia: 185-201.

López Alsina, F. 1988. La ciudad de Santiago en la Alta Edad Media, Santiago de Compostela, Concello de Santiago de Compostela.

LÓPez PereirA, J. E. 1993. Mármoles romanos de la iglesia de Santiago de Alfonso III: determinación de su procedencia, Madrider Mitteilungen 34, Madrid: 275-281.

Montenegro RÚA, E. J. 2005. El descubrimiento y las actuaciones arqueológicas en Santa Eulalia de Bóveda. Estudio historiográfico y documental de los avatares de un Bien de Interés Cultural, Lugo, Concello de Lugo.

Moralejo, S. 2004. La Reutilización e influencia de los sarcófagos antiguos en la España medieval. In: Franco Mata, A., Williams, J. (Eds). Patrimonio artístico de Galicia y otros estudios: homenaje al profesor Dr. Serafín Moralejo Álvarez, Santiago de Compostela, Xunta de Galicia: 279-288. 
NúÑEZ RoDRÍGUEZ, M. 1978. Arquitectura prerrománica, Santiago de Compostela, COAG.

PARODI, A. 1994. Les églises dans le paysage rural du haut Moyen Age en Languedoc oriental (IX ${ }^{\mathrm{e}-X I \mathrm{e}^{\mathrm{e}}}$ s.). In: L'environnement des églises et la topographie religieuse des campagnes médiévales. Actes du IIIe congrès international d'archéologie médiévale (Aixen-Provence, 28-30 septembre 1989), Paris: 107-121.

PerciVAL, J. 1997. Villas and Monasteries in Late Roman Gaul, Journal of Ecclesiastical Studies 48 (1), Cambridge: 1-21.

PÉREZ LOSADA, F. 1991. Os asentamentos na Galicia romana. In: Historia de Galicia I, A Coruña, Hércules Ediciones: 403-442.

PÉREZ LosAdA, F. 2002. Entre a cidade e a aldea. Estudio arqueo-histórico dos "aglomerados secundarios" romanos en Galicia, A Coruña, Museo Arqueolóxico Provincial.

PÉreZ Outeiriño, B. 1979. Ara procedente de San Mamede de Urros (Allariz), Boletín Auriense IX: 295-300.

Quirós, J. A.; FernÁNDEZ, M. 2001. La evolución de las técnicas constructivas en Asturias en la Edad Media. In: Actas del V Congreso de Arqueología Medieval Española, Valladolid: 371-382.

Quirós, J. A.; FernÁndez, M. 2012. Para una historia social de la arquitectura monumental altomedieval asturiana. In: Caballero, L., Mateos, P., García de Castro, C. Asturias entre visigodos y mozárabes. (Visigodos y Omeyas, VI - Madrid, 2010), Madrid, CSIC: $27-53$

RAMIL GONZÁLEZ, E. 2000. I Campaña de excavación arqueolóxica na Eirexa Vella - Bares (Mañón), Brigantium, 12: 215-218.

RAMIL GonZÁLEZ, E. 2003. Villa romana de Bares. Escavación arqueolóxica no xacemento Eirexa-Vella de Bares - Concello de Mañón - (A Coruña). Campaña 1997, Brigantium, 14: 185-224.

RAMIL, E.; LÓPEZ, R. 2003. A Serra da Capelada: patrimonio arqueolóxico e patrimonio natural, Brigantium, 14: 23-37.

RAMIL, E.; PICOS, F. 2002. Escavación arqueolóxica e rehabilitación arquitectónica da capela de San Xiao de Trebo, (Cariño-A Coruña) A Coruña, Deputación Provincial de A Coruña.

RIVAS, J. C. 1971. Algunas consideraciones sobre el prerrománico gallego y sus arcos de herradura geminados, Boletín Auriense, I: 61-125.

RIVAS, J. C. 1972. La capilla de San Xiao de Fontefría y su ara votiva a los Lares Viales, Boletín Auriense, II 303-311.

RIVAS, J. C. 2003. Noticia de restos prerrománicos en dos antiguos recintos sagrados ourensanos, Boletín Auriense, XXXIII: 209-241.

RIVAS, J. C.; RivAS, E. 1989. El ara romana de Suatorre de Ambía (Orense) y sus inscripciones altomedievales, Boletín Auriense, XVIII-XIX: 119-132.

RIVAs Quintás, E. 1985. A Limia: Val de Antelo e Val do Medo, Ourense, Diputación Provincial de Ourense.

Rivas, E.; Delgado, J. 1991. Un bajorrelieve visigótico en Asadur con la escena del Calvario, Porta da Aira. Revista de historia del arte orensano, 4: 9-22.
RodRíguez COLMENERO, A. 1985. Excavaciones arqueológicas en Ouvigo, Blancos (Orense), Noticiario Arqueológico Hispano, 24: 265-387.

Rodríguez Colmenero, A. 1993. Historia del arte romano de Galicia. In: Galicia. Arte prehistórico y romano, A Coruña, Hércules Ediciones: 237-540.

Rodríguez Colmenero, A. 2005. Arte y civilización en la Gallaecia romana. In: Arte y Cultura de Galicia y Norte de Portugal. Arqueología I, Vigo, Nova Galicia: 9-47.

Rodríguez Lovelle, M.; López QuirogA, M. 1991. ¿Elementos prerrománicos inéditos en Queizás, Verin, e Baños de Molgas? Larouco, 1: 191-195.

SÁNCHEZ PARDO, J. C. 2012. Los contextos de fundación de las iglesias tardoantiguas en Galicia (ss. V-VIII): substratos arqueológicos, distribución y significados, Antiquité Tardive, 20: 255-273.

SASTRE, I. 2009. El altar en la arquitectura cristiana hispánica. Siglos V-X. Estudio arqueológico. Tesis doctoral inédita, Madrid, Universidad Autónoma de Madrid.

SASTRE, I. 2011. La reutilización de epígrafes romanos en la Hispania tardoantigua: los altares cristianos y la polémica ara de Guadix. In: Carbonell Manils, J., Gimeno Pascual, H., Moralejo Álvarez, J. L. (eds.), El monumento epigráfico en contextos secundarios. Procesos de reutilización, interpretación y falsificación, Barcelona, Universitat Autónoma de Barcelona: $67-87$

Sobrado, J. M. 2010. Las aras romanas de Amoexa (Antas de Ulla, Lugo), Larouco, 5: 215-216.

Soto ARIAS, P.; LESTÓN GóMEZ, M. 1992. Intervención arqueológica en la Iglesia de Santa María de Dexo, Abrente, 23-24:125-135.

SuÁrez Otero, J. 1999. Apuntes arqueológicos sobre la formación del "Locus Sanctus Iacobi" y los orígenes del urbanismo medieval. In: Valdez, F. (ed.) Actas del curso sobre la Península Ibérica y el Mediterraneo entre el siglo XI y XII, Aguilar de Campoo, Fundación Santa María la Real: 11-42.

SuÁrez Otero, J. 2004. Iria, Padrón, Santiago. Geografía mítica y realidad arqueológica. In: Almazán, V. (dir.), Padrón, Iria y las tradiciones jacobeas, Santiago de Compostela, Xunta de Galicia: 245-272.

SuÁrez Otero, J.; CAAmaño Gesto, J. M. 2003. Santiago antes de Santiago. In: Portela Silva, E. (dir.) Historia de la Ciudad de Santiago de Compostela, Santiago de Compostela, Concello de Santiago de Compostela: 23-48.

TOMOS 2012. Escavación arqueolóxica, consolidación acondicionamento para a posta en valor do xacemento arqueolóxico de Igrexa Vella de Santa Comba de Louro (Valga, Pontevedra) CT 102A. Memoria técnica da intervención. Informe depositado en la Dirección Xeral de Patrimonio de la Xunta de Galicia.

Utrero, M. A. 2006. Iglesias tardoantiguas y altomedievales en la Península Ibérica: análisis arqueológico y sistemas de abovedamiento, Madrid, CSIC.

Utrero, M. A.; SASTRE, I. 2012. Reutilizando materiales en las construcciones de los siglos VII-X. ¿Una posibilidad o una necesidad?, Anales de Historia del Arte, Vol. 22, Num. Especial (II): 309-323. 
V.V.A.A. 2012. Enciclopedia del Románico en Galicia: Pontevedra, Aguilar de Campoo, Fundación Santa María la Real.

V.V.A.A. 2013. Enciclopedia del Románico en Galicia: A Coruña, Aguilar de Campoo, Fundación Santa María la Real.

VeIGA, J. M.; SOBRINO, J. 2012. Espenuca: inscrición, edificios e lugares máxicos, Anuario Brigantino, 35: 5998.

Vidal Álvarez, S. 2004. Frontal de sarcófago. Igrexa de San Sadurniño de Goiáns, Portosín, Porto de Son, A Coruña. In: Singul, F., Suárez, J. (eds.), Até o confin do mundo: diálogos entre Santiago e o mar, Vigo, Museo do mar: 82-83.

WARD-PERKINS, B. 1999. Re-using the Architectural Legacy of the Past, entre idéologie et pragmatisme. In: Brogiolo, G. P., Ward-Perkins, B. (eds). The idea and ideal of town between Late Antiquity and the Early Middle Ages, Leiden, Brill: 225-244.

WiCKHAM, C. 2012. Asturias entre visigodos y mozárabes. Observaciones finales. In: Caballero, L., Mateos, P., García de Castro, C. Asturias entre visigodos y mozárabes: (Visigodos y Omeyas, VI - Madrid, 2010), Madrid, CSIC: 475-478.

WiLLIAMS, H. 1998. Monuments and the past in early Anglo -Saxon England, World Archaeology, 30 (1): 90108.

Xusto Rodríguez, M. 2000. Iglesia vieja de Xinzo de Limia (Ourense). Intervención arqueológica y lectura histórica, Restauración y rehabilitación, 37: 2633.

Yzquierdo, R. 1993. Arte Medieval (I), A Coruña, Hércules Ediciones. 